CASE REPORT

\title{
A Case of Coronary Artery Spasm Associated with Lisdexamfetamine Use
}

\section{Himali V Gandhi, Adam H Skolnick, Harmony R Reynolds*}

Cardiovascular Clinical Research Center, Leon H. Charney Division of Cardiology, Department of Medicine, NYU School of Medicine, New York, USA

*Corresponding author: Dr. Harmony R Reynolds, Saul J Farber Associate Professor of Medicine, Associate Director, Cardiovascular Clinical Research Center, Leon H. Charney Division of Cardiology, Department of Medicine, NYU School of Medicine, New York, USA, E-mail: harmony.reynolds@nyumc.org

\section{Introduction}

Coronary artery spasm is a cause of myocardial infarction with non-obstructive coronary arteries (MINOCA). Coronary spasm may occur spontaneously or in response to prescribed or illicit drugs. Myocardial injury and cardiomyopathies have been reported in association with the use of stimulants in children and adults with attention deficit hyperactivity disorder (ADHD) [1,2]. However, a prospective study of a small cohort of 15 adults taking lisdexamfetamine for six months did not show adverse effects on myocardial structure or function on serial imaging [3]. To date, no cases of coronary vasospasm, myocarditis or cardiomyopathy have been reported in association with lisdexamfetamine. The purpose of this report is to highlight a case of MINOCA associated with lisdexamfetamine use.

\section{Case Report}

A 48-year-old woman with history of ADHD was awakened by new onset, severe chest pain which prompted her to come to the emergency department (ED). The initial heart rate was 88 and blood pressure was $147 / 53$. There was intermittent ventricular bigeminy. Troponin I was initially undetectable and then elevated to $1.7 \mathrm{ng} / \mathrm{mL}$ six hours later, followed by a gradual decline. The initial electrocardiogram, obtained during chest pain, demonstrated normal sinus rhythm with subtle, less than $1 \mathrm{~mm}$ ST elevation in the inferior leads. Subsequent ECGs, obtained after chest pain ceased, showed resolution of ST segment elevation, followed by T wave inversion in the same leads". These tracings have been added as Figure 1. Her initial echocardiogram demonstrated normal global left ventricular wall motion and normal ejection fraction. She was taken for cardiac catheterization for evaluation of NSTEMI. Cardiac catheterization revealed angiographically normal vessels (Figure 2) and mid inferior wall hypokinesis on left ventriculography (Figure 3). A spasm provocation test was not performed due to concerns about risk from induced spasm.

Of note, the patient started taking $30 \mathrm{mg}$ of lisdexamfetamine as needed for two months prior to admission. She typically took this medication intermittently, on an as needed basis. However, she took lisdexamfetamine once a day for three days prior to admission. She denied any new psychological, emotional, or physical stressors, history of depression, or major life events. Additional medical history included gastroesophageal reflux disease. She was a non-smoker with normal blood pressure, normal body mass index, normal blood glucose, and no history of premature coronary artery disease in the family. The most recent lipid panel, obtained 6 months before the event, demonstrated cholesterol of $266 \mathrm{mg} / \mathrm{dL}$, an LDL of 148 $\mathrm{mg} / \mathrm{dL}$, and an HDL of $90 \mathrm{mg} / \mathrm{dL}$. There was no history of cocaine use.

Aside from lisdexamfetamine, her only medications were famotidine and dexlansoprazole. The patient had been taking Vyvanse for ADHD intermittently for two months prior but had started taking it every day for the last three days prior to the chest pain episode.

Cardiac MRI showed the absence of late gadolinium enhancement and increased T2 signal hyperintensity (Figure 4). Left ventricular wall motion and ejection fraction were

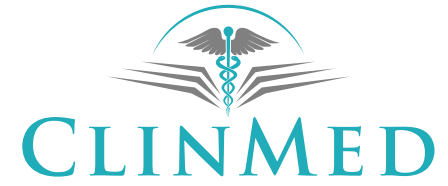

INTERNATIONAL LIBRARY
Citation: Gandhi HV, Skolnick AH, Reynolds HR (2017) A Case of Coronary Artery Spasm Associated with Lisdexamfetamine Use. Int J Clin Cardiol 4:095. doi.org/10.23937/2378-2951/1410095 Received: November 21, 2016; Accepted: April 10, 2017; Published: April 13, 2017

Copyright: (C) 2017 Reynolds H, et al. This is an open-access article distributed under the terms of the Creative Commons Attribution License, which permits unrestricted use, distribution, and reproduction in any medium, provided the original author and source are credited. 


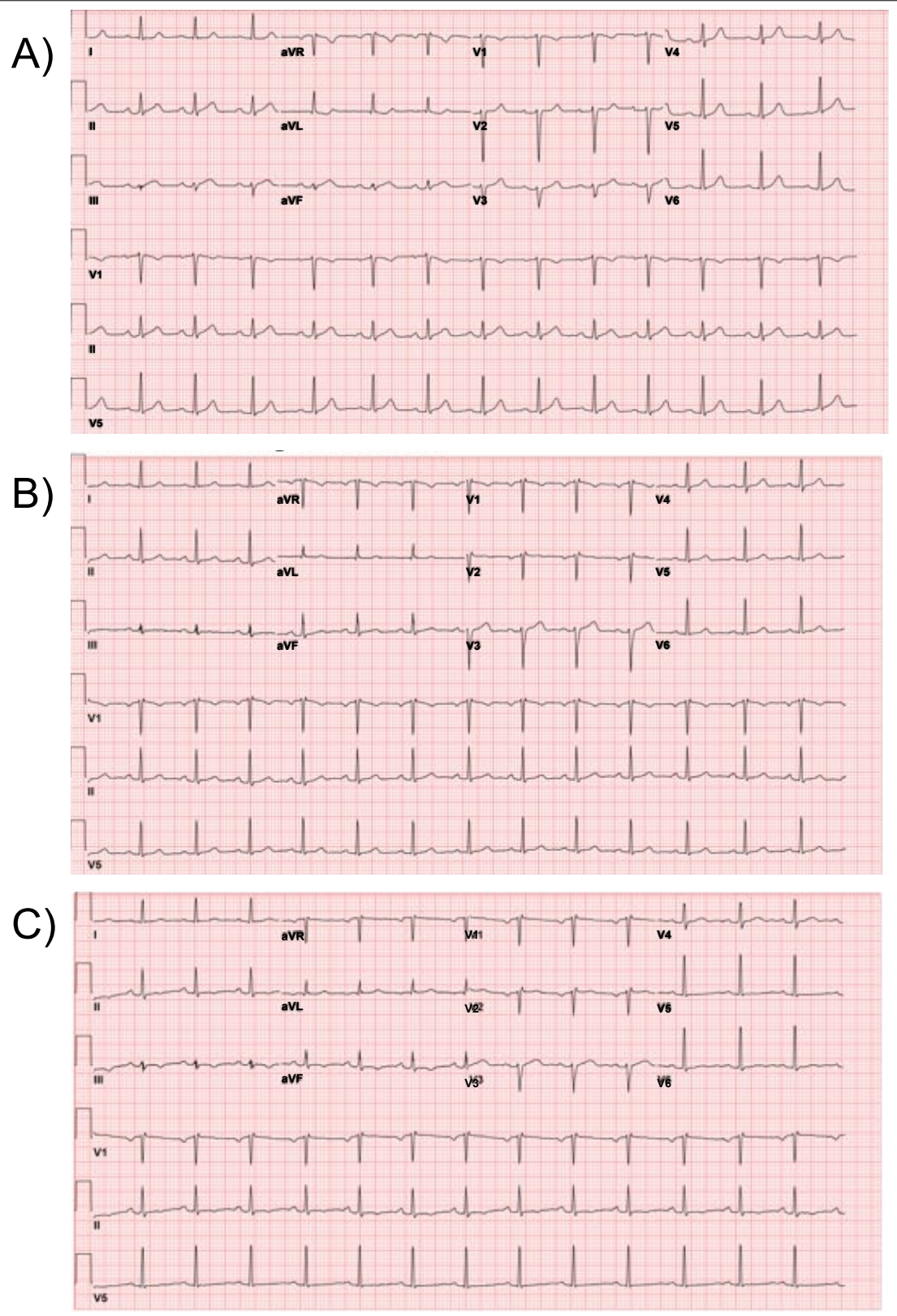

Figure 1: A) On arrival to the ED during chest pain episode. Subtle, less than $1 \mathrm{~mm}$ ST elevation in inferior leads; B) 6 hours after arrival to the ED during chest pain. Resolution of ST segment elevation; C) 24 hours after arrival to the ED and resolution of chest pain. T wave inversions in the inferior leads.

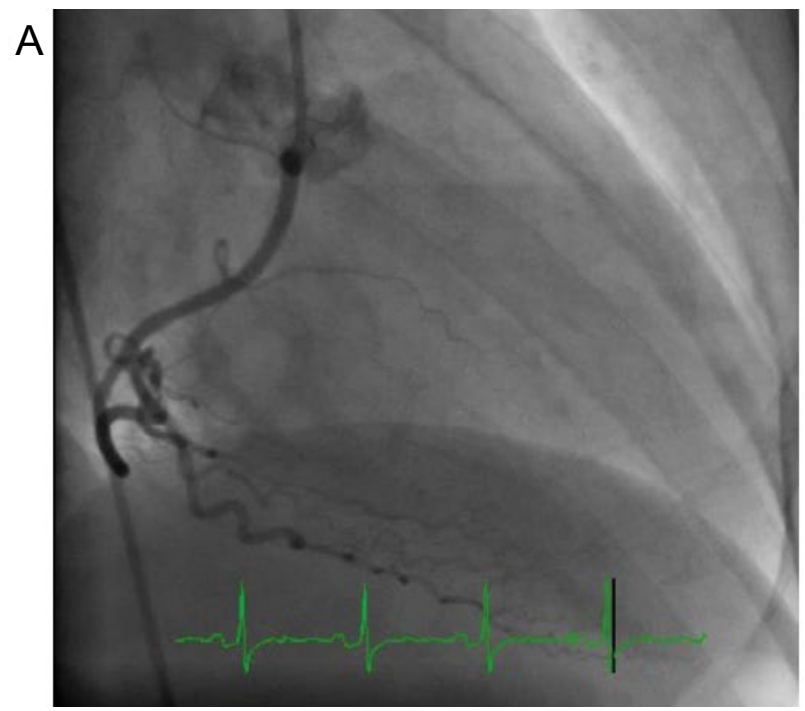

B

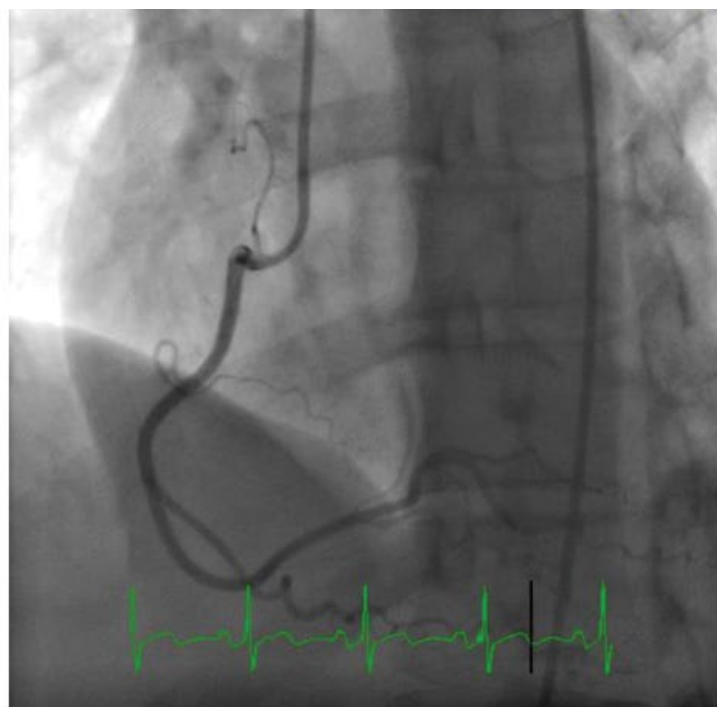

Figure 2: Coronary angiography of A) PDA; B) RCA showing non-obstructive coronary arteries. 

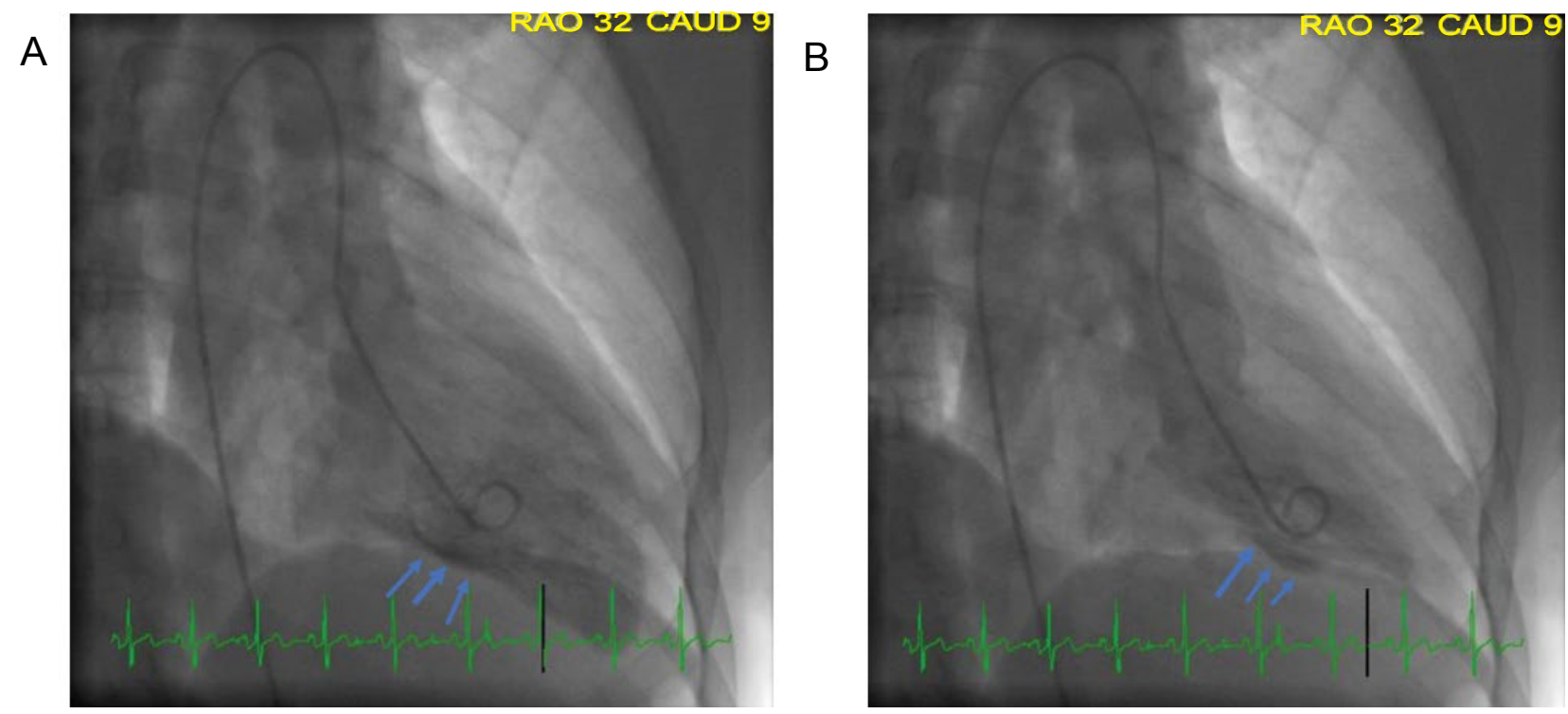

Figure 3: Left ventriculogram in A) Diastole; B) Systole showing mid inferior wall hypokinesis.
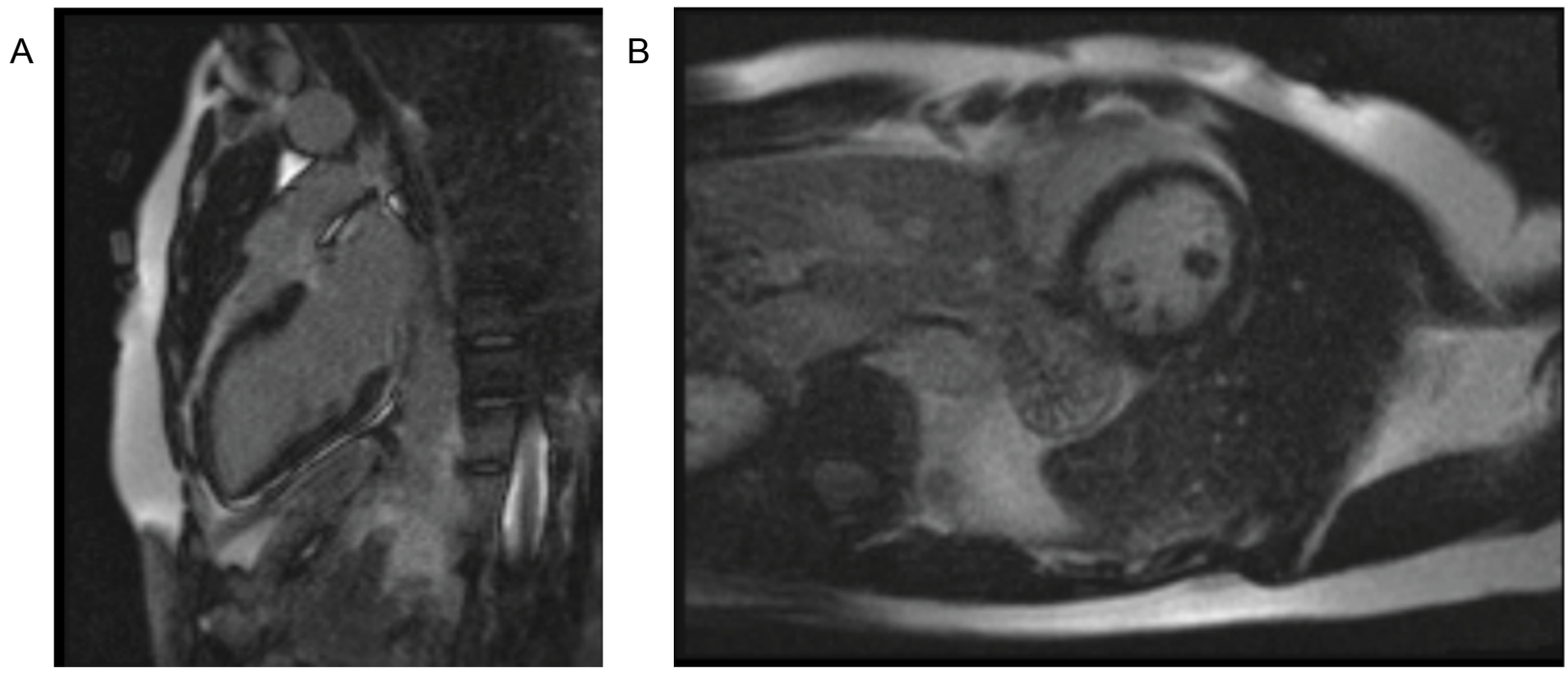

Figure 4: CMR showing absense of LGE A) Two-chamber view; B) Short axis view.

normal. A computed tomography coronary angiogram was normal, without any coronary atherosclerosis. Lisdexamfetamine was discontinued. There has been no recurrence of chest pain for over a year following the event.

\section{Discussion}

Most Mls are caused by rupture of erosion of a fixed atherosclerotic plaque with subsequent thrombus formation or a supply-demand mismatch in the setting of a significant fixed atherosclerotic occlusion. However, some cases of $\mathrm{Ml}$ are not associated with significant atherosclerotic occlusion or plaque rupture and show normal or non-obstructed vessels on angiography (stenosis severity $\leq 50$ percent). The differential in these cases includes, but is not limited to, occult plaque rupture or erosion, coronary artery spasm, takotsubo syndrome, and myocarditis. In this case, there was no atherosclerotic plaque on $\mathrm{CT}$, ruling out plaque rupture. There was also no evidence of myocarditis on MRI. Focal takotsubo syndrome was on the initial differential diagnosis given inferior wall hypokinesis on left ventriculogram. However, the wall motion abnormality was very limited, clearly falls within one coronary territory, and was associated with ST elevation in the corresponding leads on the ECG.

Transient ST elevation in the absence of atherosclerosis and in combination with transient, mild ST elevation corresponding to the area of wall motion abnormality suggests coronary artery spasm as the cause of $\mathrm{Ml}$ in this case. Spasm testing was not undertaken due to transient, though mild, ST elevation during chest pain, consistent with ACC/AHA guidelines [4] and due to concerns about risk of testing [5].

The temporal association with use of lisdexamfetamine, an amphetamine, suggests strongly that vasospasm occurred as an adverse effect of this medication. Amphetamines produce indirect sympathetic activation by releasing nor epinephrine, dopamine, and serotonin from the central nervous system as well as cardiovascular effects including but not limited to varying degrees of 
vasoconstriction, tachycardia, proarrhythmia and potentiation of myocardial ischemia [6]. Neither of the other medications taken by the patient, famotidine and dexlansoprazole, has been reported to be associated with coronary vasospasm.

We believe the duration of ischemia during the episode of coronary spasm was sufficiently short that scar formation did not occur, and therefore there was no late gadolinium enhancement on cardiac MRI. There was no evidence of myocardial edema on T2-weighted imaging. This may relate to the suboptimal sensitivity of T2-weighted imaging for myocardial edema. Newer methods such as T1 mapping improve sensitivity for edema but T1 mapping was not performed in this case [7].

We report this case to alert clinicians to the possibility of coronary vasospasm leading to myocardial infarction associated with stimulants, even in the absence of known cardiac disease.

\section{Conclusion}

Coronary artery spasm should be suspected in patients on stimulants who present clinically with myocardial infarction and have non-obstructive coronary artery disease.

\section{References}

1. Westover AN, Halm EA (2012) Do prescription stimulants increase the risk of adverse cardiovascular events?: A systematic review. BMC Cardiovasc Disord 12: 41.
2. Won S, Hong RA, Shohet RV, Seto TB, Parikh NI (2013) Methamphetamine- Associated Cardiomyopathy. Clinical Cardiol 36: 737-742.

3. Hammerness P, Zusman R, Systrom D, Surman C, Baggish A, et al. (2013) A cardiopulmonary study of lisdexamfetamine in adults with attention-deficit/hyperactivity disorder. World J Biol Psychiatry 14: 299-306.

4. Anderson JL, Adams CD, Antman EM, Bridges CR, Califf RM, et al. (2007) ACC/AHA 2007 guidelines for the management of patients with unstable angina/non-ST-elevation myocardial infarction: a report of the American College of Cardiology/American Heart Association Task Force on Practice Guidelines (Writing Committee to Revise the 2002 Guidelines for the Management of Patients With Unstable Angina/Non ST-Elevation Myocardial Infarction): developed in collaboration with the American College of Emergency Physicians, the Society for Cardiovascular Angiography and Interventions, and the Society of Thoracic Surgeons: endorsed by the American Association of Cardiovascular and Pulmonary Rehabilitation and the Society for Academic Emergency Medicine. Circulation 116: e148-e304.

5. Isogai $\mathrm{T}$, Yasunaga $\mathrm{H}$, Matsui $\mathrm{H}$, Tanaka $\mathrm{H}$, Ueda $\mathrm{T}$, et al. (2015) Serious cardiac complications in coronary spasm provocation tests using acetylcholine or ergonovine: analysis of 21512 patients from the diagnosis procedure combination database in Japan. Clin Cardiol 38: 171-177.

6. Ghuran A, Nolan J (2000) Recreational drug misuse: issues for the cardiologist. Heart 83: 627-633.

7. Ferreira VM, Piechnik SK, Dall Armellina E, Karamitsos TD, Francis JM, et al. (2013) T(1) mapping for the diagnosis of acute myocarditis using CMR: comparison to T2-weighted and late gadolinium enhanced imaging. JACC CardiovasC Imaging 6: 1048-1058. 